\title{
Early management of head injury: summary of updated NICE guidance
}

This Practice article by Sarah Hodgkinson and colleagues (BMJ 2014;348:g104, doi:10.1136/bmj.g104) contains an error in figures 3 and 4 (algorithms for the selection of adults and children for imaging of the cervical spine). The final box in both of the algorithms should have said: "Perform CT cervical spine scan [not head scan] within 1 hour of risk factor being identified." The correct figures are supplied here. $\Downarrow \Downarrow$

Cite this as: BMJ 2014;348:g1263

๑ BMJ Publishing Group Ltd 2014 


\section{Figures}

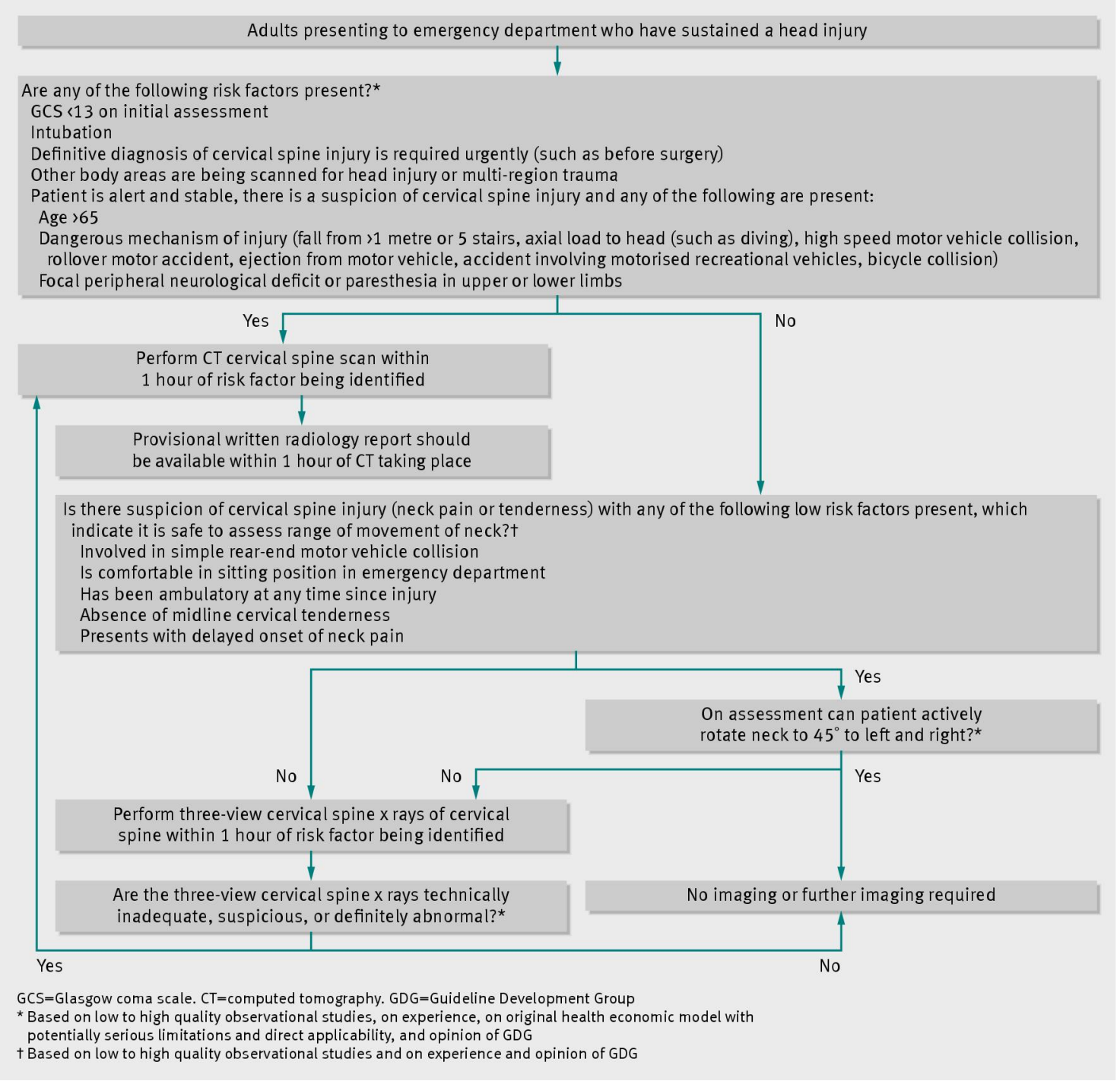

Fig 3 Algorithm 3: selection of adults for imaging of the cervical spine 


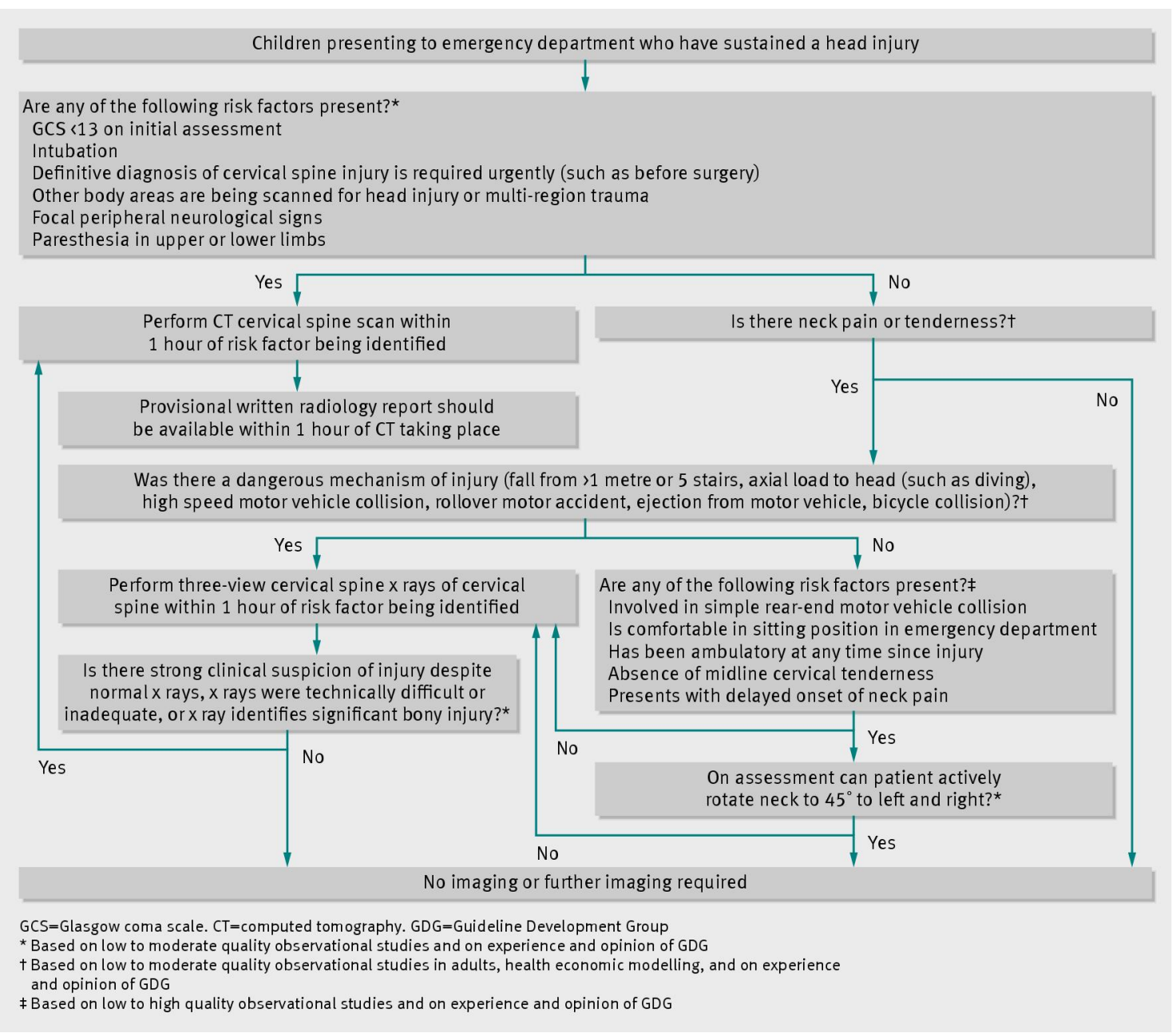

Fig 4 Algorithm 4: selection of children for imaging of the cervical spine 